\title{
Analisis Penerapan Total Quality Management dan Komitmen Organisasi dalam Meningkatkan Kinerja Perusahaan
}

\author{
Aulia Rabius Tsani*, Nurleli \\ Prodi Akuntansi, Fakultas Ilmu Ekonomi dan Bisnis, Universitas Islam \\ Bandung, Indonesia. \\ *aulia.rabius@gmail.com, lelinur@gmail.com
}

\begin{abstract}
At present the company is competing to survise in the business world, because today many companies want to maximize competitiveness through continuous improvement made by several companies that play a very important role in increasing the strength of competitiveness. Dakal global market product quality is also one of the most important elements for companies to be ableto compete. TQM is one form of company management practices that can suppress the quality paradigm witgin a company. Organizational Commitment is a force that binds individuals to take an action towards one or several goals. The purpose of this study was to determine the application of Total Quality Management in improving company performance and analysis of organizational commitment to company performance in LPKL PDAM Tirtawening. This research uses descriptive methods and case studies as well as using a quantitative approach carried out at LPKL PDAM Tirtawening, the sourch of the data used is the primary data sourch with data collection techniques namely questionnaire. Determination of respondents in filing out the research questionnaire was chosen based on the number of Managers or Section Heads of employees in LPKL PDAM Tirtawening as many as 25 respondents. Total Quality Management can improve company performance in LPKL PDAM Tirtawening.
\end{abstract}

Keywords: Application Total Quality Management, Organization Commitment, Company Performance.

\begin{abstract}
Abstrak. Saat ini perusahaan sedang bersaing untuk bertahan dalam dunia bisnis, karena saat ini banyak perusahaan yang ingin memaksimalkan daya saing melalui perbaikan terus - menerus yang dilakukan oleh beberapa perusahaanyang memainkan peran yang sangat penting dalam meningkatkan kekuatan daya saing. Dakal pasar global kualitas produk juga menjadi salah satu elemen terpenting bagi perusahaan untuk dapat bersaing.TQM adalah salah satu bentuk praktek manajemen perusahaan yang bisa menekan paradigma kualitas dalam perusahaan. Komitmen Organisasi merupakan kekuatan yang mengikat individu untuk melakukan suatu aksi untuk menuju satu atau beberapa tujuan. Tujuan penelitian ini untuk mengetahui penerapan Total Quality Management dalam meningkatkan kinerja perusahaan dan analisis komitmen organisasi terhadap kinerj perusahaan pada LPKL PDAM Tirtawening. Penelitian ini menggunakan metode deskriptif dan studi kasus serta menggunakan pendekatan kuantitatif yang dilksanakan di LPKL PDAM Tirtawening, sumber data yang digunakan yaitu sumber data primer dengan teknik pengumpulan data yaitu kusioner. Penentuan responden dalam mengisi kuesioner penelitian ini dipilih berdasarakan jumlah Manajer atau Kepala Bagian dar karyawan yang ada di LPKL PDAM Tirtawening sebanyak 25 orang responden. Total Quality Management dapat meningkat kinerja perusahaan dan komitmen organisasi dapat meningkatkan kinerja perusahaan di LPKL PDAM Tirtawening
\end{abstract}

Kata Kunci: Penerapan Total Quality Management, Komitmen Organisasi, Kinerja Perusahaan. 


\section{A. Pendahuluan}

Dalam suatu perushaan produk merupakan salah satu faktor yang penting dalam meningkatkan daya saing produk, selain produksi dan ketepatan waktu saat produksi. Saat ini banyaknya perusahaan yang bersaing untuk dapat mempertahankan eksistensis dalam dunia bisnis, dengan cara memperbaharui inovasi dari barang ataupun jasa. Persaingan semakin tajam didalam era global. Hanya perusahaan yang dapat menghasilkan kualitas barang dan jasa yang sesuai dengan tuntutan pelanggan memenangkan persaingan itu.

Perusahaan memberikan inovasi barang maupun jasa yang efektif dan efisien yang dibutuhkan oleh para konsumen dengan harga yang seminimal mungkin dan kualitasnya semaksimal mungkin.

Pada setiap orang yang bekerja dalam suatu kelompok kerja, kinerja selalu akan diharapkan dapat senantiasa baik dalam segi kualitas serta kuantitasnya.

Adapun dalam pencapaian tujuan organisasi tentu diperlukan komitmen organisasi yang baik sehingga bisa mencapai hasil yang diharapkan. Komitmen meruoakan pernyataan akan kewajiban atau keharusan yang berhubungan dengan intelektual dan emosional(Kaswan, $2012: 293)$.

Berdasarkan latar belakang masalah tersebut permasalahan yang diangkat dalam penelitian ini adalah :

1. Bagaimana penerapan Total Quality Management pada perusahaan LPKL PDAM Tirtawening?

2. Bagaimana Komitmen Perusahaan pada perusahaan LPKL PDAM Tirtawening?

3. Bagaimana penilaian Kinerja Perusahaan pada LPKL PDAM Tirtawening?

4. Bagaimana penerapan Total Quality Management dalam meningkatkan Kinerja Perusahaan pada LPKL PDAM Tirtawening?

5. Bagaimana Komitmen Organisasi dalam meningkatkan Kinerja Perusahaan LPKL PDAM Tirtawening

Tujuan penelitian yang ingin dicapai dari penelitian ini adalah:

1. Untuk mengetahui penerapan Total Quality Management di LPKL PDAM Tirtawening

2. Untuk mengetahui Komitmen Organisasi di LPKL PDAM Tirtawening

3. Untuk mengetahui Kinerja Perusahaan di LPKL PDAM Tirtawening

4. Untuk mengetahui penerapan Total Quality Management dalam meningkatkan Kinerja perusahaan

LPKL PDAM Tirtawening

5. Untuk mengetahui Komitmen Organisasi dalam meningkatkan Kinerja Perusahaan LPKL PDAM Tirtawening

\section{B. Landasan Teori}

Menurut Hansen dan Mowen (2009:17) menyatakan bahwa: "Total Quality Management adalah suatu perbaikan berkenlajutan yang mana hal ini adalah sesuatu yang mendasar sifatnya bagi pengembangan proses manufaktur yang sempurna.

Ada empat prinsip TQM yang dikembangkan oleh Hansler dan Brunell (Nasution, 2015:24), yaitu :

1. Kepuasan pelanggan

2. Respek terhadap semua orang

3. Manajemen berdasarkan fakta

4. Perbaikan berkesinambungan

Komitmen organisasi merupakan perasaan yang kuat dan erat dari seseorang tergadap tujuan dan nilai suatu organisasi dalam hubungan dengan peran mereka terhadap upaya pencapaian tujuan dan nilai - nilai (Durkin,1999). Menurut Meyer dan Allen dalam Luthan (202) yang terdapat 3 dimensi:

1. Affective Commitment

2. Continuance Commitment

3. Normative Commitment 
Menurut (Mulyadi,2007 : 321) kinerja perusahaan merupakan keberhasilan perusahaan yang secara menyeluruh untuk mencapai sasaran stategik yang direncanakan melalui penerjemah misi, visi, keyakinan dasar dan nilai strategi perusahaan.

Untuk mengukur kinerja perusahaan peneliti menggunakan metode Balanced Scorecard, dimana metode pengukuran kinerja perusahaan ini diukur dengan empat perspektif yaitu perspektif keuangan, perspektif stakeholder, perspektif proses bisnis internal, dan perspektif pertumbuhan dan pembelajaran.

Berdasarkan konsep tersebut, keempat perspektif dapat diukur dengan indicator yag sesuai menurut (Moeheriono, 2012 : 173) sebagai berikut:

1. Perspektif keuangan

- Realisasi penggunaan anggaran

2. Perspektif stakeholder

- Ukuran efisieni

- Manfaat jangka panjang kepada masyarakat

- Pengaruh terhadap tingkah laku masyarakat atau populasi sasaran

- Perubahan sikap dalam skala besar

- Kepuasan regulator atas kinerja

- Penilaian stakeholder atas kualitas output

3. Perspektif proses bisnis internal

- Kualitas teknis yang terkait dengan standar internal

- Ketepatan waktu proses

- Penilaian penyedia jasa independent atas peraturan komunikasi, kepedulian, keadilan, dan administrasi

- Kepuasan karyawan

4. Perspektid pertumbuhan dan pembelajaran

- Pelatihan dan peningkatan keahlian pegawai

- Pemanfaatan peningkatan dan akses dari teknologi informasi

- Proses atau aturan baru untuk meningkatkan pelayanan jasa

\section{Metode Penelitian}

Penelitian ini dilakukan termasuk kedalam studi kasus. Noor (2011:254) mengatakan bahwa metode penelitian adalah anggapan dasar tentang suatu hal yang dijadikan pijakan berfikir dan bertindak dalam melaksanakan penelitian.

Selanjutnya dilihat dari jenis studi, penelitian ini termasuk penelitian yang bersifat deskriptif analitis dengan pendekatan kuantitatif. Metode deskriptif dilakukan untuk mengetahui dan menjadi mampu untuk menjelaskan karakterisitk variabel yang diteliti dalam suatu situasi (Sekaran \& Bougie, 2013:258).

\section{Hasil Penelitian dan Pembahasan}

Dalam analisis deskriptif Total Quality Management, komitmen organisasi, dan kinerja perusahaan, penulis menyebarkan kuesioner sebagai alat pengumpulan data. Pernyataanpernyataan kuesioner berisi tentang penerapan Total Quality Management, komitmen organisasi, dan kinerja perusahaan di LPKL PDAM Tirtawening Kota Bandung. Kuesioner tersebut diberikan kepada kepala unit, kepala seksi bagian dan karyawan.

\section{Penerapan Total Quality Management pada LPKL PDAM Tirtawening Kota Bandung}

Pernyataan tentang Total Quality Management dalam penelitian ini dijelaskan melalui 10 pernyataan kuesioner. Dimensi Total Quality Management yaitu kepuasan pelanggan, respek terhadap semua orang, manajemen berdasarkan fakta, dan perbaikan berkesinambungan (Hansler dan Brunell dalam Nasution 2015:24).

Nilai jawaban responden terhadap Total Quality Management terletak pada kelas interval "baik" dengan memperoleh jumlah skor 841. Hal ini menunjukkan bahwa Total Quality Management pada LPKL PDAM Tirtawening Kota Bandung termasuk dalam kriteria baik. Berikut hasil 
keseluruhan tanggapan responden :

Tabel 1. Hasil Tanggapan Responden Tentang Total Quality Management

Sumber: Hasil Perhitungan 2020

\begin{tabular}{|l|c|c|}
\hline \multicolumn{1}{|c|}{ Dimensi } & Skor & Kriteria \\
\hline Kepuasan pelanggan & 260 & Baik \\
\hline $\begin{array}{l}\text { Respek terhadap semua } \\
\text { orang }\end{array}$ & 165 & Cukup Baik \\
\hline $\begin{array}{l}\text { Manajemen berdasarkan } \\
\text { fakta }\end{array}$ & 157 & Cukup Baik \\
\hline Perbaikan berkesinambungan & 241 & Cukup Baik \\
\hline
\end{tabular}

\section{Komitmen Organisasi pada LPKL PDAM Tirtawening Kota Bandung}

Pernyataan tentang komitmen orgasisasi dalam penelitian ini dijelaskan melalui 9 pernyataan kuesioner. Dimensi Komitmen Organisasi yaitu affective commitment, continuance commitment, dan normative commitment (Meyer dan Allen dalam Luthan).

Nilai jawaban responden terhadap komitmen organisasi terletak pada kelas interval " cukup baik" dengan memperoleh jumlah skor 751 . Hal ini menunjukkan bahwa sistem pengendalian manajemen pada LPKL PDAM

Tirtawening Kota Bandung termasuk dalam kriteria cukup baik. Berikut hasil keseluruhan tanggapan responden :

Tabel 2. Hasil Tanggapan Responden Tentang Komitmen Organisasi

\begin{tabular}{|c|c|c|}
\hline Dimensi & Skor & Kriteria \\
\hline Affective commitment & 332 & $\begin{array}{c}\text { Cukup } \\
\text { Baik }\end{array}$ \\
\hline Continuance commitment & 241 & Baik \\
\hline Normative commitment & 178 & Baik \\
\hline
\end{tabular}

Sumber: Hasil Perhitungan 2020

\section{Kinerja Perusahaan pada LPKL PDAM Tirtawening Kota Bandung}

Pernyataan tentang Kinerja Perusahaan dalam penelitian ini dijelaskan melalui 14 pernyataan kuesioner. Dimensi Kinerja Perusahaan yaitu perspektif keuangan, perspektif stakeholder, perspektif proses bisnis internal, dan perspektif pertumbuhan dan pembelajaran. (Moeheriono, $2012: 173$ )

Nilai jawaban responden terhadap Kinerja Perusahaan terletak pada kelas interval "cukup baik" dengan memperoleh jumlah skor 1.130. Hal ini menunjukkan bahwa Kinerja Perusahaan pada LPKL PDAM Tirtawening Kota Bandung termasuk dalam kriteria cukup baik. Berikut hasil keseluruhan tanggapan responden :

Tabel 3. Hasil Tanggapan Responden Tentang Kinerja Perusahaan

\begin{tabular}{|l|c|c|}
\hline \multicolumn{1}{|c|}{ Dimensi } & Skor & Kriteria \\
\hline Perspektif Keuangan & 82 & Cukup Baik \\
\hline Perspektif stakeholder & 482 & Cukup Baik \\
\hline $\begin{array}{l}\text { Perspektif Proses Bisnis } \\
\text { Internal }\end{array}$ & 305 & Cukup Baik \\
\hline $\begin{array}{l}\text { Perspektif pertumbuhan } \\
\text { dan pembelajaran }\end{array}$ & 261 & Baik \\
\hline
\end{tabular}

Sumber: Hasil Perhitungan 2020 
Analisis Penerapan Total Quality Management dalam Meningkatkan Kinerja Perusahaan pada LPKL PDAM Tirtawening

Berikut analisis hasil tanggapan responden lebih lanjut, sehingga bisa dilihat, bahwa Total Quality Management dapat meningkatkan kinerja perusahaan yang dilihat dan dianalisis dari dimensi per dimensi :

1. Analisis Penerapan Total Quality Management: Kepuasaan Pelanggan Dalam Meningkatkan Kinerja Perusahaan

Kepuasan pelanggan merupakan salah satu dimensi penerapan Total Quality Management. Kepuasan pelanggan bertujuan untuk memenuhi keinginan pelanggan dengan berupaya agar barang atau jasa dan pelayanan yang diberikan perusahaan sesuai dengan kebutuhan pelanggan internal dan eskternal. Dengan adanya dimensi ini pelanggan diberikan kesempatan untuk menyampaikan keluhan dan masukan kepada perusahaan yang nantinya akan digunakan untuk proses pengembangan produk dan pelayanan, oleh karena itu dimensi kepuasan pelanggan akan meningkatkan dimensi dari kinerja perusahaan yaitu perspektif Stakeholder. Jika kepuasan pelanggan telah terpenuhi dengan baik seperti kualitas produk yang baik, keluhan pelanggan direspon dengan pengembangan produk yang memenuhi kebutuhan pelanggan sehingga perusahaan akan mudah menentukan kebijakan, mengambil tindakan serta merancang prosedur pemograman sesuai dengan keluhan dan masukan dari semua konsumen. Kepuasan pelanggan yang baik pun dapat memberikan kemudahan bagi perusahaan khususnya dalam memeriksa produk dan menilai komitmen organisasi dalam memberikan pelayanan pada konsumen.

2. Analisis Penerapan Total Quality Management: Respek terhadap Semua Orang Dalam Meningkatkan Kinerja Perusahaan.

Respek terhadap semua orang bertujuan untuk membina hubungan baik dengan karyawan, melibatkan seluruh karyawan untuk berpartisipasi dalam mencapai visi dan misi perusahaan. Maka dimensi respek terhadap semua orang akan meningkatkan dimensi dari kinerja perusahaan yaitu perspektuf pertumbuhan dan pembelajaran. Dengan adanya dimensi TQM ini maka komunikasi pada bagian organisasi akan berjalan lancar sesuai dengan prosedur perusahaan, sehingga manajer dapat mengembangkan karyawan, membimbing dan melatih karyawan, serta menangani keluhan karyawan agar karyawan mempunyai kualitas yang baik dalam menjalankan kegiatan di perusahaan. Serta dapat menangani keluhan karyawan agar karyawan mempunyai kualitas yang baik dalam menjalankan kegiatan di perusahaan.

3. Analisis Penerapan Total Quality Management: Manajemen Berdasarkan Fakta Dalam Meningkatkan Kinerja Perusahaan

Manajemen berdasarkan fakta memiliki fungsi dalam pengambilan keputusan oleh perusahaan berdasarkan fakta yang terjadi di lapangan untuk kepentingan perusahaan. Serta memberikan perubahan secara terus-menerus sehingga pengambilan keputusan harus mengikuti perkembangan zaman. Adanya dimensi manajemen berdasarkan fakta pada TQM maka dimensi ini dapat meningkatkan kinerja perusahaan yaitu adanya perubahan terus-menerus yang mengakibatkan keputusan diambil dengan perkembangan zaman yang akan mempengaruhi perencanaan perusahaan.

4. Analisis Penerapan Total Quality Management: Perbaikan Berkesinambungan Dalam Meningkatkan Kinerja Perusahaan.

Perbaikan berkesinambungan merupakan dimensi dari Total Quality Management yaitu dimana perusahaan melakukam peningkatan sumber daya dan kualitas sistem perusahaan secara berkesinambungan untuk memajukan perusahaan. Sistem komunikasi yang diterapkan di perusahaan sangat terbuka antara jabatan dan divisi. Perusahaan juga melakukan pemantauan dan menganalisis terhadap kemajuan dan kemunduran yang terjadi selama ini padaperushaan.

5. Analisis Komitmen Organisasi dalam Meningkatkan Kinerja Perusahaan pada LPKL PDAM Tirtawening 
Berikut analisis hasil tanggapan responden lebih lanjut, bahwa komitmen organisasi dapat meningkatkan kinerja perusahaan yang dilihat dan dianalisis dari dimensi per dimensi :

1. Analisis Komitmen Organisasi: Affective Commitment Dalam Meningkatkan Kinerja Perusahaan

Affective Commitment menjadi salah satu dimensi dari komitmen organisasi yang bertujuan untuk melibatkan secara langsung karyawan untuk memajukan perusahaan, membebaskan karyawan berpendapat atau mengusulkan pendapat yang dapat disampaikan langsung sebagai kontribusi positif terhadap perusahaan dan memajukan perusahaan.

2. Analisis Komitmen Organisasi: Continuance Commitment Dalam Meningkatkan Kinerja Perusahaan

Continuance Commitment bertujuan untuk memberikan komitmen tinggi untuk karyawan untuk tudak meninggalkan perusahaan dan mempunyai tanggung jawab kepada perusahaan, dan memberikan kenyamanan karyawan untuk tetap diperusahaan.

3. Analisis Penerapan Sistem Pengendalian Manajemen: Pusat Laba Dalam Meningkatkan Kinerja Manajerial

Pusat laba mempunyai fungsi untuk manajer dalam menyusun laba, berpartisipasi dalam operasi pusat laba sehari-hari, dan manajer mempunyai wewenang untuk melakukan evaluasi pada laba. Pusat laba berdampak pada kinerja manajerial khususnya pada dimensi perencanaan dan evaluasi, dengan adanya pusat laba maka kinerja manajer dalam menilai, memeriksa dan mengukur laba dapat meningkat.

4. Analisis Komitmen Organisasi: Normative Commitment Dalam Meningkatkan Kinerja Perusahaan

Normative Commitment memberikan kewajiban untuk karyawan memberikan kontribusi positif untuk perusahaan dan karyawan untuk tetap tinggal di perusahaan demi kemajuan perusahaan. Adanya dimensi ini bisa membuat karyawan mempunyai rasa tanggung jawab yang tinggi untukmelaksanakan pekerjaannya dengan maksimal.

\section{Kesimpulan}

Berdasarkan hasil penelitian yang dilakukan untuk mengetahui bagaimana penerapan Total Quality Management dan Komitmen Organisasi dalam kaitannya kinerja perusahaan pada LPKL PDAM Tirtawening, maka dapat ditarik kesimpulan sebagai berikut :

1. Penerapan Total Quality Management pada LPKL PDAM Tirtawening termasuk dalam kriteria baik. Hal ini dapat dilihat dari dimensi yang digunakan dalam menerapkan total quality management yaitu: kepuasan pelanggan, respek terhadap semua orang, manajemen berdasarkan fakta, dan perbaikan berkesinambungan.

2. Komitmen Organisasi pada LPKL PDAM Tirtawening termasuk dalam kriteria baik. Hal ini dapat dilihat dari dimensi yang digunakan dalam komitmen organisasi yaitu: affective commitment, continuance commitmet, dan normative commitment

3. Kinerja perusahaan pada LPKL PDAM Tirtawening termasuk dalam kriteria baik. Hal ini dapat dibuktikan pada dimensi yang digunakan dalam kinerja perusahaan, yaitu: perspektif keuangan, perspektif stakeholder, perspektif proses bisnis internal, perspektif dan pembelajaran.

4. Penerapan Total Quality Management mampu meningkatkan kinerja perusahaan. Hal itu dapat ditunjukkan dari penerapan Total Quality Management pada LPKL PDAM Tirtawening. Perusahaan memenuhi keinginan pelanggan dengan berupaya agar produk yang diberikan perusahaan sesuai dengan kebutuhan pelanggan internal dan eskternal, membina hubungan baik antar karyawan dengan manajer, membuat keputusan berdasarkan fakta di lapangan, dan melakukan perbaikan berkesinambungan sehingga dapat meningkatkan kinerja perusahaan.

5. Penerapan Komitmen Organisasi mampu meningkatkan kinerja perusahaan. Hal itu dapat ditunjukkan dari penerapan komitmen organisasi pada LPKL PDAM Tirtawening. karyawan sudah baik dalam memberikan kontribusi positif terhadap perusahaan, dan 
karyawan berkompeten untuk memajukan perusahaan agar dapat meningkatkan kinerja perusahaan.

\section{E. Saran}

\section{Saran Operasional}

Berdasarkan analisis yang telah dilakukan oleh penulis, maka penulis mecoba untuk memberikan saran-saran yang diharapkan dapat menjadi masukan bagi perusahaan dan peneliti selanjutnya, yaitu sebagai berikut:

1. Pada aspek yang ada di Total Quality Management yaitu manajemen berdasarkan fakta memperoleh skor terendah. Perubahan selalu terjadi secara terus-menerus, maka perubahanpun harus terus mengikuti perkembangan zaman, oleh karena itu perusahaan harus membuat keputusan dan tindakan dengan tepat, sehingga manajer mampu meningkatkan kualitas produk dan pelayanan yang diberikan kepada masyarakat.

2. Sebaiknya perusahaan lebih sering melibatkan karyawan dalam berbagai kegiatan, agar karyawan pun merasa terlibat untuk memajukan perusahaan, perusahaan juga harus selalu memberikan kontribusi positif kepada pekerja, dan karyawan pun harus memberikan kontribusi yang positif bagi perusahan.

3. Sebaiknya kinerja yang dilakukan oleh perusahaan harus selalu memuaskan bagi para regulato, dengan menghasilkan kualitas atau hasil produk dan jasa dari perusahaan mendapatkan penilaian positif dari para stakeholder. Perusahaan juga harus selalu siap menghadapi perubahan sikap dalam skala besar, dan perusahaan harus selalu siap untuk menghadapi pengaruh dari tingkah laku masyarakat atau populasi sasaran. Memperhatikan manfaat terhadap masyarakat dalam waktu jangka panjang dan sering mengggunakan sistem yang efisien dalam segi biaya, sumber daya, dan waktu.

\section{Saran Pengembangan Ilmu}

Penulis menyadari bahwa penelitian ini masih ada kekurangan. Diharapkan kepada peneliti selanjutnya untuk dapat melakukan penelitian dengan menggunakan atau menambah variabel lainnya seperti kinerja perusahaan dan strategi bisnis, dengan begitu penelitian ini dapat mengembangkan ilmu pengetahuan.

\section{Daftar Pustaka}

[1] Abdurrahman, Fathoni. 2006. Metodologi Penelitian dan Teknik Penyususnan Skripsi. Jakarta: Rineka Cipta

[2] Angelos, Pantouvakis and Psomas, Evangelos. 2015. Exploring Total Quality Management Applications Under Uncertainty: A research agenda for the shipping industry. Journal of Maritime Economics \& Logistics. London.

[3] Blocher. Chen dan Lin. (2000). Manajemen Biaya. Terjemahan oleh Susty Ambarriani. Penerbit Salemba Empat, Jakarta.

[4] Brief, A. P. dan S. J. Motowidlo. 1986.Prosocial Organizational Behaviours.Academy of Management Review 11(4):710-72

[5] 2015. Manajemen Mutu Terpadu. 2015. Bogor. Ghalia Indonesia.

[6] Goetsch, D.L \& Davis, S, 1994. Introduction to Total Quality, Quality, Productivity, Competitiveness, Englewood Cliffs, NJ, Prentice Hall International Inc

[7] Hansen dan Mowen. 2009. Akuntansi Manajerial. Buku 1 edisi 8. Jakarta: Salemba Empat.

[8] Hasibuan, M. (2003). Manajemen Sumber Daya Manusia, Jakarta : PT.Bumi Aksara.

[9] Husein Umar, 2005. Metode Penelitian. Jakarta : Salemba Empat

[10] Indrawan, Rully \& Yaniawati, Raden Poppy. 2014. Metodologi Penelitian,

[11] Bandung : PT. Refika Aditama.

[12] Junqueira. Dutra. Filho and Gonzaga. 2016. The effect of strategic choices and management control systems on organizational performance. Revista Contabilidade \& Financas. Journal of Gale Business and Economics Collection 2019.

[13] Kasiram, Moh. 2008. Metodologi Penelitian. Malang: UIN-Malang Pers. 
[14] Luthans, Fred. "Perilaku Organisasi”. Edisi Sepuluh. Yogyakarta : Andi.2006.

[15] Mangkuprawira. 2011. Manajemen Sumber Daya Manusia Strategik. Bogor: Ghalia

[16] Indonesia.

[17] Mardiono, Lisa dan Eric Wibisono, Christien Jolanda. 2011. Pengukuran Kinerja Menggunakan Model Performance Prism (Studi Kasus di Perusahaan Makanan. Proceedings 6th Nastional Industrial Engineering Conference (NIEC-6). Surabaya.

[18] Meyer, John P., D.Ramona Bobocel Natalie J. Allen. 1991. Development of Organizational Commitment during the First Year of Employment : A Longitudinal Study of Pre-and Pos-EbtryInfluences. Journal of Management, Vol.17, No.4

[19] Miceli, M. P. dan J. P. Near. 1985. Characteristics of Organizational Climate and

[20] Milica and Milos. 2013. Perfomance Management and Employee Satisfaction..

[21] Mulyana, Deddy, M.A., Ph.D. 2010. Metode Penelitian Kualitatif. Jakarta : Rosda.

[22] Narimawati, Umi. 2008. Metodologi Penelitian Kualitatif dan Kuantitatif, Teori dan Aplikasi. Bandung: Agung Media

[23] Nasution. 2005. Manajemen Mutu Terpadu. Edisi kedua. Bogor. Ghalia Indonesia

[24] Nazir.Mohammad,Ph.D.(2011). Metode Penelitian. Jakarta : Ghalia Indonesia

[25] Rivai, Veithzal dan Sagala Ella Jauvani. 2009. Manajemen Sumber Daya Manusia untuk Perusahaan dari Teori ke Praktik. Jakarta: PT Raja Grafindo.

[26] Satibi, Iwan. 2012. Manajemen Publik dalam Perspektif, Teoritik, dan Empirik. Bandung: Unpas Press.

[27] Seng, Ratny. Arshad and Arif Mohammad; Gaoliang, Tian. 2018. Studying the Relationship of "Soft" and "Hard" Total Quality Management Elements with Service Quality in Service Firms. The Journal of Developing Areas. Nashville.

[28] Sekaran \& Bougie. (2013). Edisi 5, Research Methods for Business: A skill Building Approach. New York: John wiley@Sons.

[29] Sekaran, Uma. 2011. Research Methods For Business (Metode Penelitian Untuk Bisnis). Jakarta: Salemba Empat.

[30] Simamora, Henry. 2012. Akuntansi Manajemen, Edisi Ketiga. Riau: Star Gate Publisher.

[31] Sugiyono. 2013. Metode Penelitian Bisnis. Bandung: Penerbit Alfabeta.

[32] Stoner A. F. J \& Freeman, E. 1992. Management. London: Prentice Hall International

[33] Sopiah, 2008. Perilaku Organisasi, Yogyakarta: Andi offset.

[34] Tjiptono, Fandy dan Anastasia Diana. (2003). Total Quality Management. Edisi Revisi. Yogyakarta: Andi Offset.

[35] Wiener, Y. 2013. Commitment in Organizations: A Normative View, Academy of Management Review, Vol 7 No.3.

[36] Yuwono, Sony.dkk. 2002. Petunjuk Praktis Penyusunan Balanced Scorecard: Menuju Organisasi yang Berfokus pada Strategi. Jakarta: PT Gramedia Pustaka Utama. 